\title{
Predicting Individual Research Produc- tivity: More than a Question of Time
}

Note: An earlier version of this paper was presented at the annual meeting of the Administrative Sciences Association of Canada in Banff in June, 2006.

Jack K. Ito

University of Regina

Céleste M. Brotheridge

Université du Québec à Montréal

\begin{abstract}
Despite professors' education and socialization and the significant rewards they receive for research activities and output, the 80/20 rule seems to apply; that is, there exists a system of stars who produce a disproportionate volume of research such that most research tends to be undertaken by a small percentage of the academy (Erkut, 2002). Although a growing body of research seeks to address this imbalance, studies of research productivity have tended to reveal its institutional and non-behavioural antecedents. As a result, there exists very little research that considers the strategies that individuals employ to improve their personal research productivity. This exploratory, questionnairebased study of a sample of Canadian professors attempts to address this gap by examining the relationship among a number of strategies, what professors report as being their average annual number of publications over the past five years, and their perceptions of their level of research productivity. Not surprisingly, in this study, we found that the amount of time that individuals invested in research activities predicted their level of research productivity. Additionally, strategically focusing one's research positively influenced journal publication levels, both directly
\end{abstract}


and through its interaction with seeking resources (such as research grants). A strategic focus also positively predicted self-perceived research productivity through its interaction with managing ideas. Finally, although the perceived need to free up time from teaching and committee work was negatively related to journal publication levels, it was positively related to perceptions of productivity.

\section{RÉSUMÉ}

Malgré l'importance accordée à la recherche par les universités, la règle des 80/20 s'applique toujours : la majorité de la recherche est menée par une minorité de professeurs (Erkut, 2002). Les études antérieures sur la productivité des chercheurs se sont surtout concentrées sur les antécédents institutionnels, accordant peu d'attention aux stratégies individuelles visant à améliorer la productivité personnelle. Cette étude exploratoire vise à répondre à cette lacune. L'enquête révèle que le nombre d'heures qu'un individu investit dans les activités de recherche est un prédicteur du niveau de productivité. De même, l'adoption d'une stratégie de focalisation des recherches est associée à un plus haut niveau de publication dans les revues scientifiques, en particulier pour les chercheurs qui ont également fait des recherches de financement (par exemple pour des subventions de recherche). En outre, l'interaction entre la focalisation stratégique des recherches et la gestion des idées favorise la perception de soi-même comme un chercheur productif. Enfin, le sentiment de devoir réduire le temps d'enseignement et de service à la collectivité s'est avéré négativement corrélé au niveau de publication dans les revues scientifiques, mais positivement corrélé à la perception de soi comme chercheur productif.

"Publish or perish!" is an imperative that is well known to university professors (Gray \& Birch, 2000). The emphasis on research as a central mission of universities can be partly associated with William von Humboldt, a German minister of education in the early $19^{\text {th }}$ century, who believed that research competence should be a central factor in the recruitment of university professors (Moxley, 1992). Today, an institution's research reputation is a fundamental component of its prestige and legitimacy, both of which help it to obtain human and financial resources (Hu \& Gill, 2000). The relationship between research and the resources allocated to institutions is particularly explicit in the United Kingdom, where the Research Assessment Exercise (RAE) is promoted as a rational means of directing research toward national objectives. This approach is continually evolving in order to address emerging measurement and philosophical problems as well as its dysfunctional effects (e.g., Henkel, 1999). For example, the significant role of publication in peer reviewed journals, especially top tier 
publications, in RAE assessments can be problematic in emerging disciplines (Stewart, 2005). Also, the strong connection between RAE evaluations and the allocation of research funds to departments may cause significant changes to unit cultures as well as increases in stress levels and identity problems for those designated as "research inactive" (Henkel, 1999). More recently, Australia announced plans to introduce a similar type of program that directs funding to "quality” research (the Research Quality Framework; RFQ).

Although American universities have been evaluated and ranked since 1925 (Brooks, 2005), the link between research and resource allocation is much weaker than in Great Britain. Nevertheless, despite various measurement issues, the emphasis on evaluating research has become widespread over the past several years (Milem, Berger, \& Dey, 2000). This agenda is driven to the individual level through the criteria used for selection, tenure, and promotion decisions and through the socialization process where personal fulfillment in scholarly roles includes research output. These systems are designed to encourage research contributions, if not from everyone, then from most faculty members. The evaluation of one's contributions includes input measures such as the value of research grants obtained, mentoring graduate students, helping colleagues develop ideas, serving as manuscript reviewers, and output measures such as peer-reviewed journal articles, presentations, chapters in edited books, and authored books. The relative weight of these contributions has tended to vary by discipline (Brooks, 2005). Although services such as offering feedback on coworkers' manuscripts may be valued and recognized within an institution, they are not amenable to being counted and compared across institutions. As such, much of the focus of inter-institutional comparisons is on the number of articles appearing in peer-reviewed journals, often with an emphasis on top tier journals, despite the fact that an article appearing in a lower ranked journal may emerge as a "top article" (Smith, 2004).

Despite socialization and reward processes, a system of "stars" who produce a disproportionate amount of research has emerged (Erkut, 2002). Although this pattern is similar across disciplines, mean productivity is higher in the physical and health sciences and in engineering than in other disciplines such as the social sciences (Fairweather, 2002; Ontario Task Force on Resource Allocation, 1994). What seems surprising is not the existence of stars, but rather that the average research productivity of the majority of professors is relatively low (Jalongo, 1985; Boice \& Jones, 1984; Lewis, 1967; Moxley, 1992). This phenomenon has been documented for many decades through large scale surveys. For example, Lazersfeld and Thielens, Jr. (1958) reported that, of the 2451 social scientists in American four year colleges, 28\% had not published any articles, 15\% had published one or two articles, and 56\% had published three or more articles in their careers. Centra (1979), in a study of 453 faculty, reported that the median number of publications over a five year period for social sciences faculty peaked at 1.7 (with the medians varying by age grouping but peaking for those with 13 to 20 years of teaching experience). Using U.S. Department of Education data (N 
$=11,013)$, Mooney (1991) reported that 70\% of faculty in research and doctoral universities and only 35\% in comprehensive four year institutions published at least one article in the two year period 1986 - 1987. These patterns reasonably reflect research productivity in academia today. For example, Dennis, Valacich, Fuller, and Schneider (2006) found that the publication rates of recent Ph.D. graduates in the information systems field was highly concentrated. Although $2 \%$ had published three or more articles in a selection of 20 elite journals, only $11 \%$ had published at least one article in the same journals over a six year period. Finally, in his study of Canadian business schools, Erkut (2002) found relatively low research productivity levels and a high reliance on stars, which makes business schools more vulnerable to losing their stars and rising stars and experience difficulty in recruiting promising academics. All disciplines face this prospect as the academic bulge of "boomers" retires.

Given the foregoing and the consequent need to increase the research performance of the majority of the academy, there is increasing interest in understanding the drivers behind research productivity. Existing research has tended to focus on institutional and non-behavioural contributors to research productivity. For example, institutional level studies have related scholarly output to factors such as the university where one's Ph.D. was obtained (Hu \& Gill, 2000; Keith, Sundra, Babchuk, \& Johnson, 2002; Long, Bowers, Barnett, \& White; 1998; Williamson \& Cable, 2003), the reputation and scholarly output of a scholar's departmental origin and placement (Long et al., 1998), and prior industry experience (Lin \& Bozeman, 2006). The potential for a relationship between research productivity and such variables may stem from institutional processes, such as the socialization of scholars into a research culture. Individual level predictors of research productivity later in one's career include the number of pre-appointment publications and presentations (Park \& Gordon, 1996) and the productivity level of one's dissertation advisor (Williamson \& Cable, 2003).

Whereas the foregoing literature makes a valuable contribution to our understanding of the broader factors associated with research productivity, it does not consider the strategies that individuals employ as a means of enhancing their personal research productivity. Several articles, primarily written by or about seasoned researchers, address this latter issue (Blaszczynski, 2001; Dauphinee, 1999; Gray, 1999; Gray \& Birch, 2000; Kiewra \& Creswell, 2000; Scott, 2003). They offer a broad description of personal experiences and suggestions for increased productivity as well as guidance for academic writing (Boice, 1996; Moxely, 1992). Although these articles are often directed towards new faculty members, many of their implications seem appropriate for faculty members at any level. In addition, several studies have compared faculty members who have high productivity levels with those with average or low productivity on a variety of dimensions such as the amount of time they spend on research $(\mathrm{Hu} \&$ Gill, 2000; Hunter \& Kuh, 1987; Tschannen-Moran, Firestone, Hoy, \& Johnson, 2000). 
However, the foregoing contributions did not systematically examine multiple strategies that individual faculty members employ as a means of enhancing their research productivity. This is the aim of our study. More specifically, we examine the relationship between research productivity and five strategies or factors. Although researchers may employ a wide range of strategies, those that were included in this study were consistently identified as important in the work previously cited. These five factors include (1) building a strategic focus, (2) generating ideas, (3) working toward obtaining resources such as research grants, (4) managing one's use of time, and (5) investing time in research-related activities. In this study, each of these factors (except for time invested) is treated as a multi-item variable that measures the extent to which an individual engages in the activity. We employ two broad measures of research productivity: (1) a multi-item perceptual measure, and (2) the average number of peer reviewed journal articles published per year over the most recent five year period (or less when an individual has been in a research-required position for fewer than five years).

This exploratory study endeavours to contribute to our overall knowledge of research productivity and the factors that contribute to it. It is unique in that it extends the rich detail of the personal testimony and interview articles to a somewhat broader sample. As well, in contrast with existing studies that have focused on a few variables but consistent with the view that researchers are likely to employ multiple strategies concurrently, this study considers a broad range of such variables as well as their interaction effects. We also test whether the well-established relationship between the amount of time spent on research and productivity levels is moderated by other personal strategies. Thus, we investigate whether some strategies make better use of an investment in time. Finally, although this study has theoretical interest, it also has practical implications for researchers wishing to improve their productivity.

\section{RESEARCH STRATEGIES}

\section{Building a Strategic Focus}

The development of a research program is an important consideration in becoming a productive researcher (Dauphinee, 1999). A research program identifies and explores a research area or domain through a series of related studies that address certain questions and yield further avenues for research. Research strategies have been characterized in various ways, including the "systematizer" in which there is significant order in exploring a domain (Kiewra \&Creswell, 2000), which is similar to the scalpel approach described by Whicker, Kronenfeld, and Strickland (1993). Gary Latham's almost exclusive focus on goal setting and its correlates over the past several decades is an example of this type of research strategy. Other researchers may develop research agendas that shift with changing issues in the business, social, or political environment, but that remain within a domain (such as the study of careers). The domain itself may be very 
highly specialized or relatively broad. In contrast with these two strategies that take full advantage of cumulative experience, the strategy that seems to be least promising is a "shotgun" approach (Whicker, Kronenfeld, \& Strickland, 1993). A researcher who uses this strategy explores multiple research topics and domains without any particular area of focus. A strategic focus may be supported by a plan that sets out short and longer-term goals for research, publication (including publication outlets and their requirements), and resources such as research grants and teaching releases (Scott, 2003). The development of an appropriate strategy may be initiated and supported during an individual's graduate student years and extended through at least the initial segment of one's career by a mentor, often one's dissertation supervisor (Williamson \& Cable, 2003).

\section{Generating Ideas}

The systematic development of research ideas can contribute to one's research productivity. This process may include wide-ranging reading, creative contemplation, and interaction with academics, professionals, and students (Scott, 2003). This process enables researchers to keep abreast of current issues and encourages the sort of cross-fertilization that potentially yields new streams and directions in a research program. In the "double helix model" researchers shift between the "academic world and the real world of politics and policy making" (Whicker et al., 1993, p. 76-77). In this reinforcing cycle, scholarly publications serve to achieve recognition and build reputation in the broader audience, which in turn serves to enhance academic opportunities (for example by facilitating access to decision-makers). This is likely a common strategy in the field of management, where researchers address emerging issues and develop not only theory but also its practical implications. Hunter and Kuh (1987) found that, relative to "average" researchers, highly performing researchers tended to take greater advantage of fortuitous opportunities. This requires good judgment and the capacity to recognize and take advantage of opportunities to the greatest extent possible.

\section{Seeking Resources}

Although, given the nature of their research, some researchers may not need research grants and contracts to support their research agendas, others require financial resources in order to obtain capital equipment and software, travel expense reimbursement, and student support. Moreover, the ability to obtain research funding is sometimes used as a mark of excellence for both individuals and their institutions, and, thus, may serve as an input productivity measure (Fairweather, 2002). Seeking financial resources is complemented by the benefits of (1) collaborating with other researchers so as to create a stronger grant funding proposal and make a richer contribution to the field (Dauphinee, 1999), (2) gathering data that can result in multiple publications, and (3) carefully planning for and working towards proposal and journal deadlines. 


\section{Managing the Use of One's Time}

Time demands on faculty members include teaching and research as well as committee work (Reichert, Daniels-Race, \& Dowell, 2002). The positive relationship between the amount of time spent on research and scholarly productivity has been consistently upheld (Marsh \& Hattie, 2002; Hu \& Gill, 2000). Scholars (e.g., Skolnik, 2000) have stressed the importance of spending time on research activities in generating publications. More specifically, a study of Canadian researchers found that those with the highest 25\% of publications worked eight hours longer per week than those with the lowest $25 \%$ of publications. Whereas two thirds of these extra hours came from working a longer week, the remaining hours came from a reduced teaching load (Lennards, 1987, Ontario Task Force on Resource Allocation, 1994). In investigating the possibility of the "complete scholar," Fairweather (2002) found that the combination of the excellent teacher and the excellent researcher was relatively rare. In particular, time-consuming teaching methods, such as those that require extensive collaboration with colleagues, higher student contact hours, and heavy teaching loads inhibited research output. Thus, one's success in limiting involvement in administrative work and teaching (either in the form of fewer classes, fewer preparations, or both) may be a factor in increasing research productivity. The ability to secure research time is also related to the opportunity to enjoy a reasonable work-life balance, a characteristic of many productive scholars (Kiewra \& Creswell, 2000). However, in a survey of information systems professors, $\mathrm{Hu}$ and Gill (2000) found that, rather than having fewer teaching and service responsibilities, productive researchers simply worked more hours than their less productive counterparts. Thus, research productivity is associated with two aspects of managing the use of one's time: (1) reducing teaching and committee loads (i.e., reducing other demands on one's time), and (2) increasing the number of hours invested in research activities (i.e., the total number of hours spent on research).

The foregoing discussion suggests the following hypothesis:

Hypothesis 1: Building a strategic focus, generating ideas, seeking resources, reducing teaching and committee loads, and spending time on research activities are all positively associated with research productivity.

The potential for interaction effects between strategies also exists. For example, researchers who employ strategies such as building a strategic focus may also make better use of their time. Fairweather (2002) implied this possibility and suggested that "faculty members with higher classroom assignments typically are able to publish at greater than average rates when they also have a research grant, which gives them the opportunity to publish from their ongoing research work" (p. 43). Thus it is hypothesized that

Hypothesis 2: The positive association between the amount of time spent on research and research productivity is stronger at higher levels of strategic focus, idea management, resource seeking, and reduced teaching and committee loads. 
As suggested in the testimonial and interview-based articles noted earlier, there may exist clusters of activities that are mutually reinforcing. In particular, building a strategic focus may serve as an effective umbrella strategy that both reinforces and is reinforced by effective idea management, resource acquisition, and reduced teaching and committee loads. This would suggest that

Hypothesis 3: The positive association between strategic focus and research productivity is stronger at higher levels of idea management, seeking resources, and reduced teaching and committee loads.

\section{RESEARCH DESIGN}

\section{Sample}

Questionnaires were mailed to a total of 278 university professors employed at a university located on the Canadian prairies during the final exam period of the fall semester. The university is a medium sized comprehensive institution that offers undergraduate and master's degrees in all faculties and Ph.D. degrees in some faculties. In addition to being advised that participation in the survey process was voluntary and confidential, professors were asked to respond only if research formed a central part of their responsibilities. Of the total of 55 professors who responded to the questionnaire, the final sample consisted of 47 individuals due to missing values and the elimination of two outlier cases. A total of nine respondents (19\%) were female, and 38 (81\%) were tenured. Approximately $31 \%$ and $74 \%$ of the population from which the sample was drawn was female and tenured, respectively. It is generally known that females tend to publish less than males; however this is partly a function of discipline given that there are a disproportionate number of males in the physical sciences and engineering. We do not expect the difference in the sample and population gender distribution to significantly influence the relationships among variables.

The respondents had an average tenure of 13.6 years in a position requiring research. They represented a broad spectrum of academic units in this university, with approximately 13 or $28 \%$ of the sample being drawn from science and engineering (compared to the $31 \%$ of the population).

\section{Measures}

Research productivity. The studies cited earlier employed a wide variety of measures of research productivity. For example, some used a relatively narrow but objective standard of the number of articles published in a specified list of important journals in the field(s) of study (e.g., Long, et. al., 1998). Others considered a range of publications in several categories, including articles in peerreviewed journals, book chapters, and authored and edited books (e.g., Marsh $\&$ Hattie, 2002). The length of the publication period under consideration also diverged considerably. Some studies considered a relatively short publication period, for example, a three-year time frame (Marsh \& Hattie, 2002). Others 
considered a longer period; for example, whereas Long et al. (1998) considered research output in a 12 year period, Williamson and Cable (2003) included the first six years in a tenure track position in their study of early career research. Moreover, the objectivity of the data collection process ranged from a count of articles appearing in selected journals over a period of time (Long et. al., 1998) to self-reports subject to verification (e.g., departmental performance reports, Marsh \& Hattie, 2002) or self-reports of publication levels obtained through primary (Hu \& Gill, 2000) or secondary sources (Fairweather, 2002).

This study used two self-report productivity measures. One was a self-assessment "perception of productivity" variable that consisted of seven items measured on an "agreement" five point Likert-type scale $(\alpha=.96)$. A sample item is: "I consider myself to be a productive researcher." This subjective measure was expected to tap not only the quantity but also the quality of research productivity. Moreover, understanding how people perceive their own research productivity is in itself a useful undertaking, since it may help us understand the discourse underlying processes such as performance evaluation. Our study also included a quantitative, self-report question that asked respondents to specify how often they had published articles in peer-reviewed journals, book chapters, books, papers in conference proceedings, and articles in practitioner or trade journals. Respondents were asked to identify the number of publications in each of these categories: in an average year, in the past five years, and in total. However, the number of articles published in peer reviewed journals may in itself be a useful indicator of research productivity, given its frequent use as a measure of research productivity and its strong relationship with perceptions of research productivity in this study $(\mathrm{r}=.47, \mathrm{p}<.001)$. For this reason and since we were interested in strategies currently in use, we considered the number of articles published in peer reviewed journals over the past five years as our measure of research productivity. We calculated respondents' annual research productivity over a five-year period by dividing their number of publications by five (for respondents who had been in a research-required position for at least five years) or making the necessary adjustments for those reporting less than five years in a research position.

Predictors of Research Productivity. The variables and the items for the predictors of research productivity were generated by the second author from the literature cited above (see the appendix). The five-point Likert type scales asked respondents to rate "how true the following statements are for you in general" ( $1=$ definitely not true, $5=$ definitely true). Strategic focus was measured by four items $(\alpha=.63$; sample item: I have a clear research focus in an area that fascinates me). Idea management was measured by 3 items ( $\alpha=.71$; sample item: I generate research ideas from interacting with others). Seeking resources $(\alpha=.76)$ consisted of 4 items (sample item: I seek grants and research assistants). The first aspect of time management, an ability to reduce other demands, was composed of 2 items $(\alpha=.74$; sample item: I try to limit the number of course preps that I have to do in any given semester). Time spent in research 
activities was a single item: "How many hours do you work on research projects in an average week"? In order to make as much use of the data as possible, missing values for the independent variables were replaced by the sample mean (by item). This approach is considered to be a conservative data analytic approach since it reduces the chances of finding significance for some variables. An exploratory factor analysis of the predictors of productivity revealed four factors with clear item loadings (see the appendix). The factor loadings ranged from .57 to .85 with a mean loading of .73 . There were 13 off-loadings with a magnitude of .19 or greater, with a range of .19 to .41 , with a mean of .26 (see the appendix).

\section{ANALYSIS}

Given the exploratory nature of this study, stepwise regression was used to examine the proposed relationships. Several variables known to influence productivity were entered first as control variables including respondent tenure, gender, and years of service. We also used the respondents' disciplinary area as a control variable given its known association with publication levels. For example, significant differences in mean publication rates were found in doctoral students in chemistry, psychology, and literature (Lee, 2000). This is supported by Nakhaie's (2002) finding that both males and females in the sciences published more refereed articles than their counterparts in other disciplines. Also, grants and strong faculty-graduate student ties play a significant role in research and publication in science and engineering due to high laboratory costs (Brooks, 2005). In this study, we created two broad disciplinary groupings with social sciences, humanities, and fine arts coded as 1 and engineering and science coded as 2.

The second block of variables that was entered included the five predictors of research productivity: having a strategic focus, managing ideas, seeking resources, managing one's time, and spending one's time on research. The third block of variables consisted of the seven proposed interaction effects. To manage multicollinearity, the predictors were centered about the mean (subtracting the mean from the score) and interaction effects were calculated using the centered scores (Aiken \& West, 1991). Given that interaction effects tend to be difficult to detect, following Aguinis, Beaty, Boik, and Pierce (2005), we used the $\mathrm{p}<.10$ criterion.

\section{RESULTS AND DISCUSSION}

Initial data analyses revealed that the explanation of variance was inordinately high. A further examination of the plots of research productivity revealed the presence of two individuals who reported exemplary productivity, far above the third highest productivity level (10.0 and 12.6 journal articles per year with the third highest at 7.2 per year). This suggested an outlier effect, and, when these data were removed from the analysis, the explanation of variance was 
reduced and some interaction effects were no longer significant. The removal of these two cases also decreased the average annual productivity rate over the past five years from 2.0 to 1.67 articles and the standard deviation from 2.45 to 1.58. Although we believe that exceptional performances should be included in a study of productivity, given that these two cases were clearly outliers in this sample, we did not include them in the data analyses.

Table 1 presents the means, standard deviations, and correlations among the variables. Tables 2 and 3 present the results of the regression analyses. Given that standardized regression coefficients should not be employed when an interaction is predicted (Aiken \& West, 1991), the unstandardized coefficients are presented. The variance inflation factor (VIF) scores were all less than 1.5 for the variables included Table 2, thus indicating that centering the variables about the mean was effective in limiting the effects of multicollinearity on the regression weights (e.g., Li \& Atuahene-Gima, 2001). In Table 3, when the interaction term for seeking resources and time spent on research was entered, the VIF score for seeking resources moved from 1.4 to 5.1, and the score was 4.3 for the interaction term, thus inflating these coefficients. However, the direction of the interaction is not affected nor does multicollinearity affect the incremental variance explained.

The results for the analyses in which the average number of peer reviewed articles over the last five years was employed as the dependent variable provided mixed support for the hypotheses. The finding that service length was negatively associated with recent productivity is consistent with the general belief that research productivity levels tend to be higher earlier, rather than later, in one's career. This study also confirmed the casual observation that one's discipline is a strong predictor of publication rates, with researchers in the sciences and engineering having higher levels of productivity than those in the social sciences. Of the variables proposed as predictors of productivity levels, strategic focus $(\mathrm{p}<.05)$ and the number of hours spent on research $(\mathrm{p}<.05)$ were significant. Interestingly and contrary to what was expected, the activities associated with freeing up time for research were negatively associated with productivity levels $(\mathrm{p}<.05)$.

Only one of the tested interaction effects was significant at $p<.05$ : the interaction of strategic focus and seeking resources. This finding is noteworthy in part because seeking resources was not significantly directly related to productivity levels. As shown in Table 2, the slope of the relationship between seeking resources and productivity levels is positive when strategic focus is slightly above the average score, but it is negative below that score. Thus, when strategic focus is low, higher levels of resource seeking are associated with lower performance. However, when strategic focus is high, the effect is positive (see Figure 1). ${ }^{1}$ These results support the perspective that strategic focus reinforces resource-seeking behaviour and vice versa. Moreover, in support of our "casual" observation, we found that, when strategic focus is low, resource-seeking behaviour will likely not only be futile, but may also lead to lower productiv- 
ity. In sum, a high level of strategic focus may reinforce the positive effects of

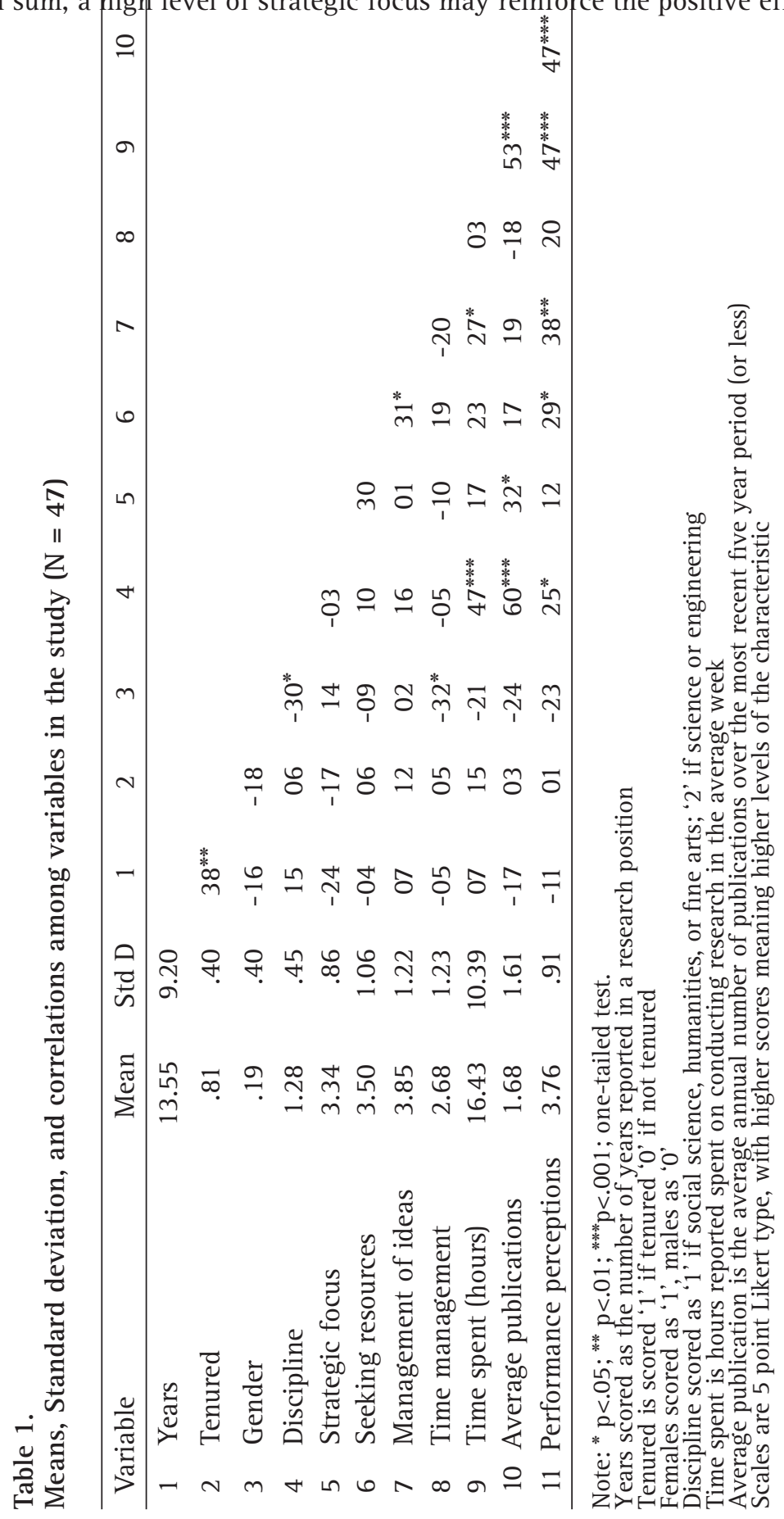


Table 2.

Unstandardized Regression Coefficients for Average Annual Number of Peer-Reviewed Journal Articles over the Past Five Years

\begin{tabular}{lll}
\hline & Main Effects & Main Effects and Interactions \\
\hline Constant & .03 & -.28 \\
Years in research & $-.05^{*}$ & $-.05^{*}$ \\
Tenured & .34 & .34 \\
Gender & -.71 & -.68 \\
Discipline & $1.64^{* * * *}$ & $1.68^{* * *}$ \\
$\mathrm{R}^{2}=.44, \mathrm{~F}(4,42)=8.27^{* * * *}$ & & \\
Strategic focus & $.47^{*}$ & $.55^{*}$ \\
Management of ideas & .03 & .08 \\
Seeking resources & -.01 & .03 \\
Management of time & -.27 & $-.30^{*}$ \\
Time spent & $.04^{*}$ & $.04^{*}$ \\
$\mathrm{R}^{2}=.17, \mathrm{~F}(5,37)=3.23$ & & $.36^{*}$ \\
Strategic focus * Ideas & & \\
$\mathrm{R}^{2}=.05, \mathrm{~F}(1,36)=5.09^{*}$ & & \\
$\mathrm{R}^{2}=.66$ & & \\
Adjusted $\mathrm{R}^{2}=.56 ; \mathrm{F}(10,36)=6.95^{* * * *}$ & & \\
\hline
\end{tabular}

Table 3.

Unstandardized Regression Coefficients for Perception of Research Productivity over the Past Five Years

\begin{tabular}{lcc}
\hline & Main Effects & Main Effects and Interactions \\
\hline Constant & 4.03 & 4.33 \\
Years in research & -.00 & -.00 \\
Tenured & -.27 & -.44 \\
Gender & -.07 & -.11 \\
Discipline & -.34 & -.29 \\
Annual journals & $.26^{*}$ & .14 \\
$\mathrm{R}^{2}=.24 \mathrm{~F}(5,40)=2.53^{*}$ & & \\
Strategic focus & -.14 & -.11 \\
Management of ideas & .29 & $.45^{*}$ \\
Seeking resources & .09 & $.67^{* *}$ \\
Management of time & $.22^{*}$ & $.20^{*}$ \\
Time spent & .02 & .03 \\
$\mathrm{R}^{2}=.20 \mathrm{~F}(5,35)=2.44$ (p<.10) & & $-.03^{* *}$ \\
Time spent ${ }^{*}$ seeking resources & & $.30^{*}$ \\
$\mathrm{R}^{2}=.06 \mathrm{~F}(1,34)=4.38 *$ & & \\
Strategic focus * Ideas & & \\
$\mathrm{R}^{2}=.07 \mathrm{~F}(1,33)=5.29 *$ & & \\
$\mathrm{R}^{2}=.57$ & & \\
Adjusted $\mathrm{R}^{2}=.41 \mathrm{~F}(12,33)=3.64^{* * *}$ & &
\end{tabular}




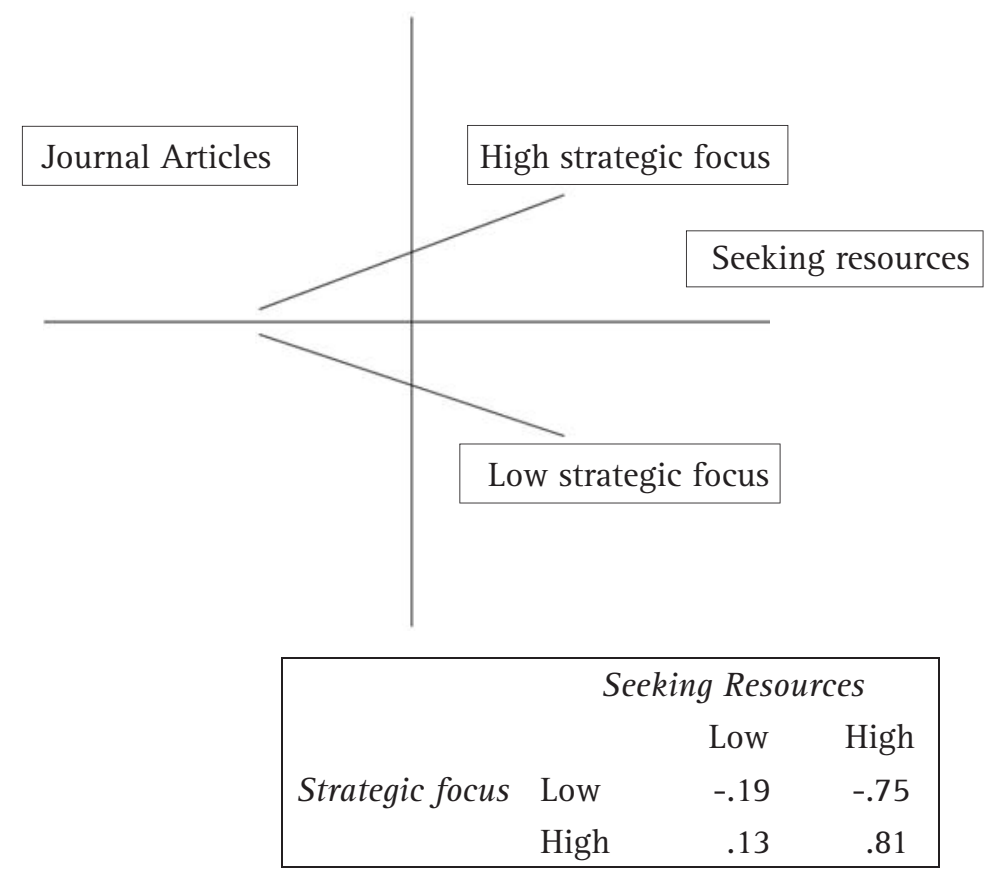

Figure 1.

Interaction Effect: Strategic Focus and Resources on Journal Articles

seeking resources, such as grants, on productivity levels. However, when there is a lack of focus, seeking resources has a negative effect on productivity levels. This could be due to difficulty in obtaining resources, investing time in seeking resources that would be better spent elsewhere, or both.

The results for the analyses in which the perceptual measure of productivity was employed as the dependent variable were different from those in which the dependent variable was the average number of peer reviewed articles over the last five years. Since the perception of research productivity is likely to be related to objective productivity, the average number of peer reviewed articles over the past five years was included in the equation. As seen in Table 3, none of the demographic variables (including the productivity measure) were significant predictors of perceptions of productivity. Of the variables proposed as direct predictors of objective productivity levels, managing ideas $(p<.05)$, seeking resources $(\mathrm{p}<.01)$, and managing time $(\mathrm{p}<.05)$ were all significant. Interestingly, the positive regression coefficient for the management of time contrasts with the negative coefficient for productivity levels.

Two of the tested interaction effects were significant. The interaction of strategic focus and idea management was significant at $p<.05$. As shown in Table 3, the slope of the relationship between the management of ideas and 
perceived performance is negative when one's strategic focus is low (roughly one and one half standard deviations below the mean); this slope, however, is positive when one's level of strategic focus is above that relatively low score (see Figure 2). Thus, a high level of strategic focus reinforces the positive effect of trying to manage idea development and vice versa. The combination of high focus and low idea management may be perceived as incongruous, resulting in feelings that productivity is not as high as it might be. Conversely, high strategic focus with a paucity of ideas may lead to perceptions of reduced contributions to the field. The data also suggest that the combination of high strategic focus and high management of ideas is an effective strategy. The scatter strategy (many ideas, little focus) is not effective, though better than having a limited number of ideas.

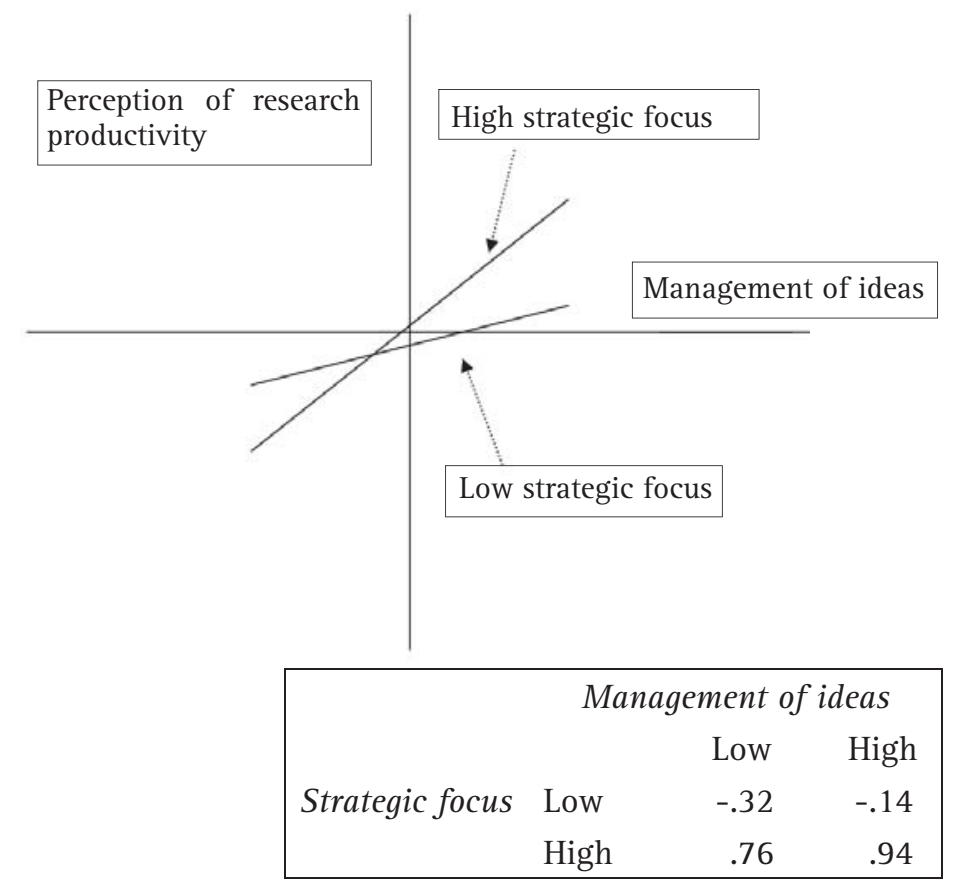

Figure 2.

Interaction Effect: Strategic Focus and Management of Ideas on Perceptions of Research Productivity

The interaction of seeking resources and spending hours in research was significant at $\mathrm{p}<.01$. In examining the pattern of interactions shown in Table 3 , on one hand it seems that when seeking resources is high, the amount of time that faculty spend on research does not affect their perceptions of their productivity levels. On the other hand, when seeking resources is low, the amount 
of time that they spend on research is positively associated with perceptions of their productivity levels (see Figure 3). This seems to imply that seeking resources (such as applying for and receiving grants) may strongly define one's perceived productivity level, whereas effort (time spent) has a limited impact on these perceptions. Conversely, when faculty do not seek resources, their perceptions of their productivity levels rely partly on the amount of time that they have spent on research activities.

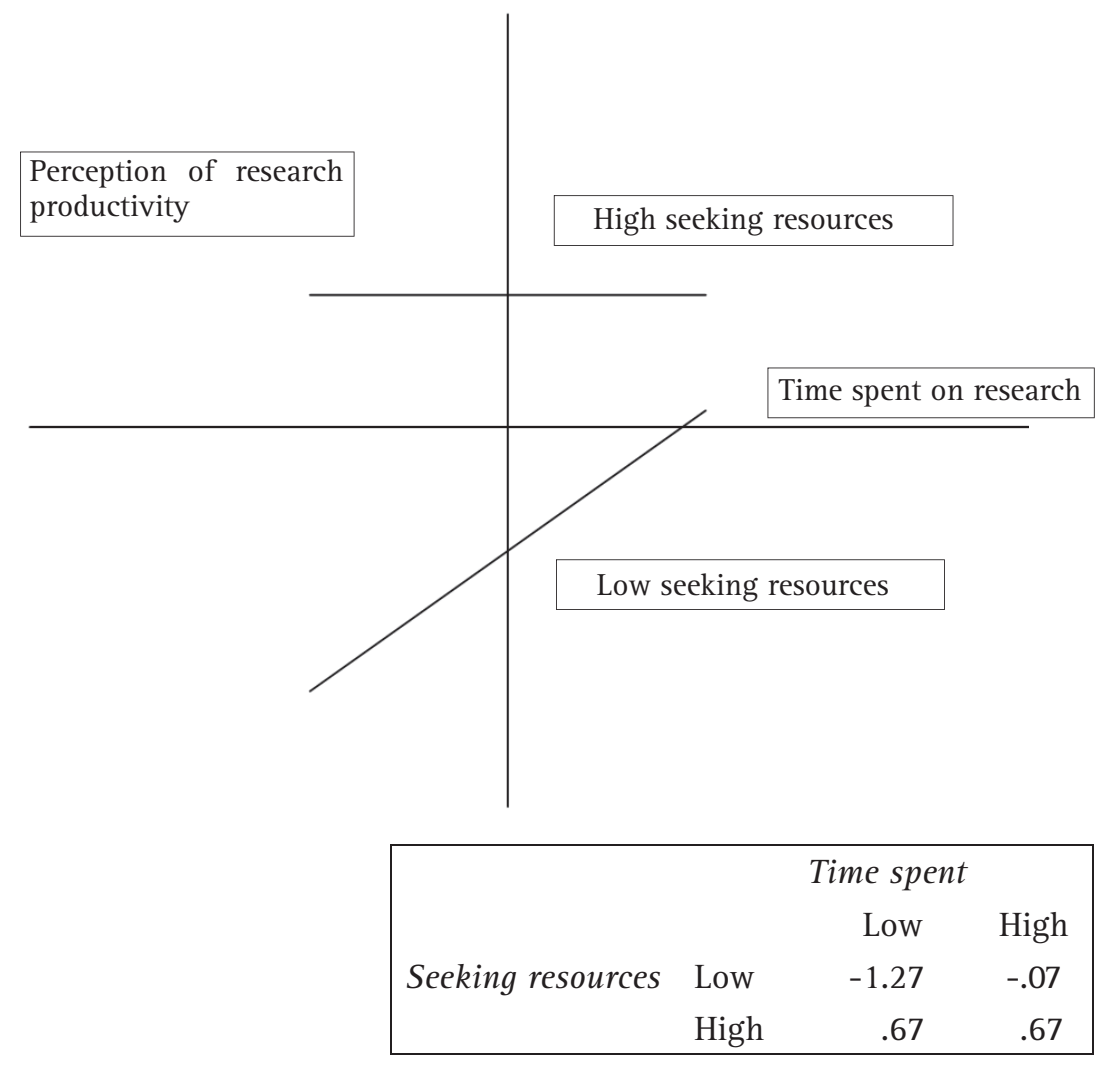

Figure 3.

Interaction Effect: Seeking Resources and Time Spent on Research on Perceptions of Research Productivity 


\section{CONCLUSIONS}

In this paper we have presented the results of an exploratory study of the factors that contribute to two aspects of research productivity: the average number of peer reviewed publications per year (within a five year period) and perceived productivity levels. A literature review revealed a set of potential predictors of research productivity including having a strategic focus, managing ideas, seeking resources, managing time (limiting committee and class preparation time), and spending time on research. This study is among the first to investigate multiple strategies in a quantitative survey.

Not surprisingly, and in support of existing research, this study found that the amount of time that faculty spent on research activities predicted both their perceptions of their productivity levels and their reported journal publication levels. Strategic focus, a variable often discussed in interviews with prominent researchers and implied in studies relating academic background to research productivity, had a significant impact on productivity, both directly and through its interaction with seeking resources (such as grants). Strategic focus also had an impact, through its interaction with managing ideas, on the perceptual measure of research productivity. These findings support the anecdotal and common sense beliefs that strategic focus is important because it reinforces the influence of building resources and framing ideas. It was interesting that one variable that is often discussed - the need to free up time from teaching and committee work - was negatively related to objective productivity, but positively related to perceptions of productivity. This may suggest that productive researchers learn how to work within the limitations of their commitments or, perhaps, how to work more efficiently. Seeking out advice on how to manage commitments may become increasingly important as a shortfall in the number of faculty emerges.

The data from two exceptionally productive researchers revealed that their responses significantly increased the variance in the productivity variables and, consequently, inflated the explanatory contributions of the independent variables. For example, their scores on strategic focus, idea management, seeking resources, time management, and hours spent on research activities were much higher than the average scores for these variables. Although the removal of these data was justifiable in this study, future studies with a larger sample size should include an appropriate number of these individuals. This would provide a much better test of theories and may help to detect interaction effects that demonstrate whether clusters of strategies are more effective than those that do not reinforce one another. Moreover, the study of exceptional or highly productive researchers may yield strategies that help researchers move beyond an average productivity level. Conversely, studying the practices of those with relatively low levels of productivity may help to identify strategies that should be avoided. 
Thus, it may be worthwhile to undertake a mixed-method study that explores research strategies in greater depth through interviews with a wide range of researchers. Additionally, since multiple paths to research productivity likely exist, it may be useful to examine the potential for several different clusters of strategies or profiles of productive researchers. ${ }^{2}$

There are a number of limitations to this study. Its exploratory nature, particularly its small sample size, limited the ability to detect effects. As a result, only strong effects were detected. For this reason, it would be useful to replicate the study with a larger sample size. Also, the productivity measures were selfreported in nature, and, although the average publication levels appear to be similar to those reported in the literature, more objective methods such as an examination of curriculum vitae or a selected journal search may have yielded additional insights. An alternative measure that considers the traditional meaning of productivity (i.e., the ratio of inputs to outputs) may also be worth exploring. An extension of this would be to examine the relationship between research inputs such as the dollar value of research grants held, the number of research assistants and Ph.D. students supervised, one's teaching load, and a range of research outputs such as conference presentations, book chapters, and peer-reviewed journal articles.

The original factor analysis left several concepts "on the table" since the items did not group cleanly. These included strategies pertaining to working habits (using blocks of time) and lifestyle (such as having a satisfactory worklife balance). However, the approach taken in this exploratory study, that is, measuring variables that were largely within the influence of individuals, may result in findings that help researchers to improve their productivity. Further investigation and the development of clusters of effective practices will be particularly important given the increasing emphasis on research output in institutions irrespective of their classification by range of degrees or by size.

In addition, the nature of professors' motivations for undertaking research and their influence on the number and type of strategies employed should be examined. For example, it is possible that, just as some students are instrumentally oriented toward their education (Brotheridge \& Lee, 2005), there exist individuals who enter academics simply for the lifestyle that it offers rather than to make a significant contribution to knowledge creation in a given discipline. $^{3}$

Finally, future research should examine the extent to which contextual and or situational factors influence researchers' productivity levels. For example, research incentive programs such as the one described Manning and Barrette (2005) may serve as extrinsic sources of motivation that increase researchers' productivity levels. Additionally, given that researchers work in and are influenced by their institutional settings, it is important to examine the influence of a given setting on individual research productivity levels. The existence of a vibrant and supportive research culture is evident in factors such as a leader's commitment to research; faculty autonomy, innovation, and self-determinism; 
and a positive group climate (Conn, Porter, McDaniel, Rantz, \& Maas, 2005; Bland, Center, Finstad, Risbey, \& Staples, 2005). In contrast, and as argued by Brotheridge (2006), researchers are unlikely to be highly productive in institutional climates in which their professional autonomy has eroded, and management oversight is characterized by control, surveillance, accountability, and market exploitation.

\section{NOTES}

1 Low and high scores were computed as one standard deviation from the average (which in the $\mathrm{Z}$ system is zero). The productivity score is simply the prediction of the contribution to the raw score of $Y$ (not standardized, etc.). This means that in the diagrams the crossing point of the vertical and horizontal axes is 0,0 ; with the left hand side of the vertical being negative or low and right hand side being positive or high.

2 The authors thank Pierre Cossette for suggesting this possibility.

3 This idea was offered at a seminar on degree purchasing held at Université Laval.

\section{REFERENCES}

Aguinis, H., Beaty, J. C., Boik, R. J., \& Pierce, C. A. (2005). Effect size and power in assessing moderating effects of categorical variables using multiple regression: A 30-year review. Journal of Applied Psychology, 90 (1), 94-107.

Aiken, L.S., \& West, S.G. (1991). Multiple regression: Testing and interpreting interactions. Newbury Park, CA: Sage.

Bland, C. J., Center, B. A., Finstad, D. A., Risbey, K. R., \& Staples, J. G. (2005). A theoretical, practical, predictive model of faculty and departmental research productivity. Academic Medicine, 80, 225-237.

Blaszczynski, C. (2001). Insights from prolific business education researchers. Delta Pi Epsilon Journal, 43(3), 113-122.

Boice, R. (1996). Procrastination and blocking: A novel, practical approach. Westport, CT: Praeger.

Boice, R., \& Jones, F. (1984). Why academicians don't write. Journal of Higher Education, 55(5), 567-582.

Brooks, R.L. (2005). Measuring university quality. Review of Higher Education, 29(1), 1-21.

Brotheridge, C. M., \& Lee, R. T. (2005). Correlates and consequences of degree purchasing. Canadian Journal of Higher Education, 35(2), 71-97.

Brotheridge, C. M... (2006). A call for autonomy: Protecting Léon Foucault's progeny from Michel Foucault's panopticon. Working Paper. 
Centra, J.A. (1979). Determining faculty effectiveness. San Francisco: Jossey-Bass.

Conn, V. S., Porter, R. T., McDaniel, R. W., Rantz, M. J., \& Maas, M. L. (2005). Building research productivity in an academic setting. Nursing Outlook, 53(5), 224-231.

Dauphinee, W. D. (1999). Developing an educational research programme. Education for Health, 12(1), 103-106.

Dennis, A.R., Valacich, J.S., Fuller, M.A., \& Schneider, C. (2006). Research standards for promotion and tenure in information systems. MIS Quarterly, 30(1), 1-13.

Erkut, E. (2002). Measuring Canadian business school research output and impact. Canadian Journal of Administrative Sciences, 19(2), 97-123.

Fairweather, J.S. (2002). The mythologies of faculty productivity. Journal of Higher Education, 73(1), 26-48.

Gray, T. (1999). Publish, don't perish: Twelve steps to help scholars flourish. Journal of Staff, Program, and Organizational Development, 16(3), 135-142

Gray, T., \& Birch, J. (2000). Publish, don't perish: A program to help scholars flourish. To Improve the Academy, 19, 268-284.

Henkel, M. (1999). The modernization of research evaluation: The case of the U.K. Higher Education, 38(1), 105-122.

Hu, W., \& Gill, G. (2000). IS faculty research productivity: Influential factors and implications. Information Resources Management Journal, 13(2), 15-25.

Hunter, D.E., \& Kuh, G.D. (1987). The "write wing": Characteristics of prolific contributors to the higher education literature. Journal of Higher Education, 58(4), 443-462.

Jalongo, M. R. (1985). Faculty productivity in higher education. Educational Forum, 49(2), 171-182.

Keith, B., Sundra, J., Babchuk, N., \& Johnson, K. (2002). The context of scientific achievement: Sex status, organizational environments, and the timing of publication on scholarship outcomes. Social Forces, 80(4), 1253-1281.

Kiewra, K. A., \& Creswell, J.W. (2000). Conversations with three highly productive educational psychologists: Richard Anderson, Richard Mayer, and Michael Pressley. Educational Psychology Review, 12(1), 135-161.

Lazarsfeld, P.F., \& Thielens, W., Jr. (1958). The academic mind. New York, NY: Free Press.

Lee, W.M. (2000). Publication trends of doctoral students in three fields from 1965-1995. Journal of the American Society for Information Science, 51(2), 139-144. 
Lennards, J. (1987). The academic profession in Canada: Summary report. Unpublished report, Department of Sociology, Glendon College, York University, North York, Ontario, Canada.

Lewis, L.S. (1967). Publish or perish: Some comments on a hyperbole. The Journal of Higher Education, 38(2), 85-89.

Li, H., \& Atuahene-Gima, K. (2001). Product innovation strategy and the performance of new technology ventures in China. Academy of Management Journal, 44(6), 1123-1134.

Lin, M-W., \& Bozeman, B. (2006). Researchers' industry experience and productivity in university-industry research centers: A "scientific and technical human capital” explanation. The Journal of Technology Transfer, 31(2), 269-290.

Long, R. G., Bowers, W. P., Barnett, T., \& White, M. C. (1998). Researcher productivity of graduates in management: Effects of academic origin and academic affiliation. Academy of Management Journal, 41(6), 704-714.

Manning, L. M., \& Barrette, J. (2005). Research performance management in Academe. Canadian Journal of Administrative Sciences, 22(4), 273-287.

Marsh, H.W., \& Hattie, J. (2002). The relation between research productivity and teaching effectiveness, The Journal of Higher Education, 73(5), 603-641.

Milem, J.F., Berger, J.B., \& Dey, E.L. (2000). Faculty time allocation: A study of change over twenty years. Journal of Higher Education, 71(4), 454-475.

Mooney, C.J. (1991). Efforts to cut amount of 'trivial' scholarship win new backing from many academics. The Chronicle of Higher Education, 37 (May 22), A1, A13, A16.

Moxley, J. M. (1992). Publish, don't perish: The scholar's guide to academic writing and publishing. Westport, CT: Praeger.

Nakhaie, M.R. (2002). Gender differences in publication among university professors in Canada. The Canadian Review of Sociology and Anthropology, 39(2), 151-179.

Park, S.H., \& Gordon, M.E. (1996). Publication records and tenure decisions in the field of strategic management, Strategic Management Journal, 17(2) 109128.

Reichert, W.M., Daniels-Race, T., \& Dowell, E.H. (2002). Time-tested survival skills for a publish or perish environment. Journal of Engineering Education, 91(1), 133-137.

Scott, J. C. (2003). Conceiving and building a sustainable research program. Delta Pi Epsilon, 45 (1), 3-16.

Skolnik, M. (2000). Does counting publications provide any useful information about academic performance? Teacher Education Quarterly, 27(2), 15-25. 
Smith, S.D. (2004). Is an article in a top journal a top article? Financial Management, 33(4), 133-149.

Stewart, J. (2005). The UK research assessment exercise. Human Resource Development International, 8(4), 489-495.

Task Force on Resource Allocation (1994). The structure of academic work. Toronto, Ontario: Ontario Council on University Affairs.

Tschannen-Moran, M., Firestone, W.A., Hoy, W.K., \& Johnson, S.M. (2000). The write stuff: A study of productive scholars in educational administration. Educational Administration Quarterly, 36(3), 358-390.

Whicker, M.L., Kronenfeld, J.J., \& Strickland, R.A. (1993). Getting tenure. Newbury Park, CA: Sage.

Williamson, I. 0., \& Cable, D. (2003). Predicting early career research productivity: The case of management faculty. Journal of Organizational Behavior, 24(1), 25-44.

\section{CONTACT INFORMATION}

Céleste M. Brotheridge

Département d'organisation et ressources humaines

École des sciences de la gestion

Université du Québec à Montréal

C.P. 6192, Succ. Centre-Ville

Montréal QC Canada H3C 4R2

Telephone: (514) 987-3000 ext. 6540

Fax: (514) 987-0407

E-mail: grimard-brotheridge.celeste@uqam.ca

Jack K. Ito (Ph.D., Washington) is a Professor in the Faculty of Business Administration at the University of Regina, Canada. His research interests include strategic human resource management with an emphasis on careers, mobility, and stress in the context of organizational and demographic change.

Céleste M. Brotheridge (Ph.D., Manitoba) is a Professor with the Écoles des sciences de la gestion at the Université du Québec à Montréal. Her research interests include emotions, bullying, and burnout in the workplace as well as the commercialization of education as it affects the work of professors. 
Appendix: Predictors of Research Productivity (Means, SD, and Factor Loadings)

\begin{tabular}{|c|c|c|c|c|c|}
\hline & & Factor 1 & Factor 2 & Factor 3 & Factor 4 \\
\hline & Mean (SD) & $\begin{array}{l}\text { Seeking } \\
\text { resources }\end{array}$ & $\begin{array}{l}\text { Management } \\
\text { of Ideas }\end{array}$ & $\begin{array}{l}\text { Strategic } \\
\text { focus }\end{array}$ & $\begin{array}{l}\text { Management } \\
\text { of Time }\end{array}$ \\
\hline $\begin{array}{l}\text { I know the deadlines for grant } \\
\text { applications and conference } \\
\text { submissions and work backwards } \\
\text { from them. }\end{array}$ & $3.88(1.34)$ & .71 & & & \\
\hline $\begin{array}{l}\text { I try to gather data that permits me } \\
\text { to publish more than one article } \\
\text { from one dataset. }\end{array}$ & 3.54 (1.58) & .66 & & & \\
\hline $\begin{array}{l}\text { I seek grants and research } \\
\text { assistants. }\end{array}$ & $3.52(1.32)$ & .70 & & & \\
\hline $\begin{array}{l}\text { I seek out opportunities to } \\
\text { collaborate with others who have } \\
\text { complementary skills. }\end{array}$ & 3.54 (1.09) & .81 & & & \\
\hline $\begin{array}{l}\text { I generate research ideas from } \\
\text { interacting with others. }\end{array}$ & $3.85(1.26)$ & & .73 & & \\
\hline $\begin{array}{l}\text { I develop and maintain a } \\
\text { professional and personal network. }\end{array}$ & 4.08 (.99) & & .72 & & \\
\hline $\begin{array}{l}\text { I have several projects in different } \\
\text { stages in progress at one time. }\end{array}$ & $4.77(.51)$ & & .80 & & \\
\hline $\begin{array}{l}\text { I have a short- and long-term } \\
\text { research plan that identifies } \\
\text { priorities, goals, and time frames } \\
\text { for research, publication, and grant } \\
\text { seeking. }\end{array}$ & $3.69(1.31)$ & & & .73 & \\
\hline $\begin{array}{l}\text { I have a clear research focus in an } \\
\text { area that fascinates me. }\end{array}$ & 4.23 (1.08) & & & .71 & \\
\hline $\begin{array}{l}\text { I have a personal mentor who } \\
\text { provides me with practical and } \\
\text { moral support. }\end{array}$ & 2.36 (1.38) & & & .57 & \\
\hline
\end{tabular}




\begin{tabular}{|c|c|c|c|c|c|}
\hline & & Factor 1 & Factor 2 & Factor 3 & Factor 4 \\
\hline & Mean (SD) & $\begin{array}{l}\text { Seeking } \\
\text { resources }\end{array}$ & $\begin{array}{c}\text { Management } \\
\text { of Ideas }\end{array}$ & $\begin{array}{l}\text { Strategic } \\
\text { focus }\end{array}$ & $\begin{array}{c}\text { Management } \\
\text { of Time }\end{array}$ \\
\hline $\begin{array}{l}\text { I examine the requirements } \\
\text { of various publication outlets } \\
\text { and target my writing to those } \\
\text { requirements. }\end{array}$ & 3.35 (1.38) & & & .62 & \\
\hline $\begin{array}{l}\text { I try not to take on too many } \\
\text { responsibilities that may interfere } \\
\text { with research (e.g., committee } \\
\text { work). }\end{array}$ & $2.48(1.39)$ & & & & .84 \\
\hline $\begin{array}{l}\text { I try to limit the number of course } \\
\text { preps that I have to do in any given } \\
\text { semester. }\end{array}$ & $2.94(1.36)$ & & & & .85 \\
\hline
\end{tabular}

I serve as a mentor for students interested in research.

I obtain feedback on my papers from colleagues.

I keep track of how much time I am $2.08(1.08)$ actually devoting to research.

I establish a daily routine regarding $2.27(1.24)$ where and when I write.

I set aside blocks of time of sufficient $2.92(1.30)$ length that permit me to concentrate on my writing.

I prepare outlines for papers before writing them.

I use productivity tools such as Endnote that help me to organize my work.

$3.79(1.29)$

3.31 (1.38) 


\begin{tabular}{|c|c|c|c|c|c|}
\hline & & Factor 1 & Factor 2 & Factor 3 & Factor 4 \\
\hline & Mean (SD) & $\begin{array}{l}\text { Seeking } \\
\text { resources }\end{array}$ & $\begin{array}{c}\text { Management } \\
\text { of Ideas }\end{array}$ & $\begin{array}{l}\text { Strategic } \\
\text { focus }\end{array}$ & $\begin{array}{c}\text { Management } \\
\text { of Time }\end{array}$ \\
\hline $\begin{array}{l}\text { I try to schedule classes that fall on } \\
\text { the same days of the week. }\end{array}$ & $2.88(1.42)$ & & & & \\
\hline $\begin{array}{l}\text { I read extensively in order to stay } \\
\text { up-to-date in my field and to generate } \\
\text { research ideas. }\end{array}$ & $3.98(1.11)$ & & & & \\
\hline $\begin{array}{l}\text { I seek out training and advice (e.g., } \\
\text { research methods, software, writing) }\end{array}$ & $2.75(1.30)$ & & & & \\
\hline $\begin{array}{l}\text { I create balance in my life and, } \\
\text { in particular, manage my stress } \\
\text { effectively. }\end{array}$ & $3.37(1.27)$ & & & & \\
\hline I enjoy the process of doing research. & $4.52(.67)$ & & & & \\
\hline
\end{tabular}

